\section{FORMAR O TREINADOR E O JOGADOR NAS CATEGORIAS DE BASE DO FUTEBOL: ENGENDRANDO NA INTERAÇÃO E/OU NA ESPECIFICIDADE?}

\author{
COACH AND PLAYER DEVELOPMENT IN YOUTH SOCCER: ENGENDERING IN \\ INTERACTION AND OR SPECIFICITY?
}
FORMAR EL ENTRENADOR Y EL JUGADOR EN LAS CANTERAS DEL FÚTBOL: ¿ENGENDRANDO EN LA INTERACCIÓN O EN LA ESPECIFICIDAD?

\author{
Otávio Baggiotto Bettega*, João Claudio Braga Pereira Machado**, \\ Alcides José Scaglia*, Cesar Vieira Marques Filho*, Larissa Rafaela Galatti*
}

Palavras chave:

Futebol.

Educação Física

e Treinamento.

Aprendizagem.

\begin{abstract}
Resumo: 0 objetivo do estudo é apresentar possibilidades de formação para o treinador e o jogador de futebol no clube a partir das particularidades de cada processo e na interação entre ambos. Indicamos ao treinador a proposta baseada na Aprendizagem ao Longo da Vida, de Peter Jarvis, que preconiza que todas as experiências vividas promovem aprendizagens moldadas pela interação do indivíduo com o mundo. Quanto ao jogador, partimos da Pedagogia Não Linear (PNL) para sustentar um processo que seja centrado no jogador e pautado no jogo, buscando oferecer um ambiente de aprendizagem representativo para o desenvolvimento do jogador. Para ambos, destacamos a necessidade de um conhecimento sistematizado no clube para estabelecer estratégias formativas e significativas para os sujeitos.
\end{abstract}

\section{Keywords:}

Football.

Physical Education and Training. Learning.

Abstract: This study presents educational possibilities for football coaches and players at their clubs, based on the particularities of each process and the interaction between them. To coaches we indicate Peter Jarvis's proposal based on Lifelong Learning, which advocates that all experiences promote learning shaped by individuals' interaction with the world. Regarding players' development, we use a player-centered and game-based approach supported by Nonlinear Pedagogy, seeking to provide a learning environment that is representative for their development. For both, we emphasize the need for systematized knowledge at clubs to establish formative and meaningful strategies for subjects.

Palabras clave: Fútbol. Educación Física y Entrenamiento. Aprendizaje.
Resumen: El objetivo del estudio es presentar posibilidades de formación para el entrenador y el jugador de fútbol en el club a partir de las particularidades de cada proceso y en la interacción entre ambos. Indicamos al entrenador la propuesta basada en el Aprendizaje a Largo Plazo de Peter Jarvis, que preconiza que todas las experiencias vividas promueven aprendizajes, moldeados por la interacción del individuo con el mundo. En cuanto al jugador, partimos de la Pedagogía No Lineal (PNL), para sustentar un proceso que sea centrado en el jugador y pautado en el juego, buscando ofrecer un ambiente de aprendizaje representativo para el desarrollo del jugador. Para ambos, destacamos la necesidad de un conocimiento sistematizado en el club para establecer estrategias formativas y significativas para los sujetos.
Universidade Estadual de Campinas (Unicamp). Campinas, SP, Brasil. E-mail: otavio.b.bettega@gmail.com; alcides.scaglia@gmail.com; cesarvmf@ hotmail.com; lagalatti@hotmail.com

${ }^{*}$ Universidade Federal do Amazonas (UFAM). Manaus, AM, Brasil. E-mail: joaoclaudiomachado@gmail.com

Recebido em: 12-11-2018 Aprovado em: 08-03-2019 Publicado em: 25-04-2019

DOI https://doi.org/10.22456/1982-8918.88087

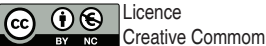




\section{INTRODUÇÃO}

A complexa missão de proporcionar possibilidades para a formação de pessoas apresenta diversos caminhos, sendo esses não lineares e dependentes da interação entre 0 indivíduo e seu ambiente de inserção ao longo do tempo (CHOW; ATENCIO, 2014; JARVIS, 2013). No caso do futebol, modalidade de elevado investimento, apreço cultural e visibilidade midiática no contexto brasileiro e internacional, a formação de treinadores e jogadores ainda enfrenta conflitos quando pensada em longo prazo. 0 clube de futebol, que atualmente figura como principal local de formação, necessita propiciar ambientes de aprendizagem significativos para treinadores e jogadores, considerando as particularidades de cada processo formativo, mas também visualizando o cenário do clube e especificamente o do treino como um contexto de interação entre treinador e jogadores, para assim sistematizar situações de aprendizagem para ambos.

Salienta-se que a escolha pela modalidade de futebol pauta-se nas experiências dos autores em processos de formação de treinadores no estado de São Paulo e de jogadores realizados no estado do Rio Grande do Sul, São Paulo e Amazonas. O estudo de Bettega e colaboradores (2015) aponta alguns princípios pedagógicos estabelecidos e desenvolvidos no processo formativo estruturado na cidade de Santa Maria/RS. Em Scaglia e colaboradores (2013) são apresentados pressupostos de uma metodologia pautada no jogo, sendo essa desenvolvida em um processo de formação de jogadores na cidade de Paulínia/SP, e no estudo de Machado e colaboradores (2019) é destacada a Pedagogia Não Linear, abordagem estabelecida no processo formativo de jogadores que é realizado na cidade de Manaus/AM. Além disso, podemos observar no texto que há referências a propostas e modelos gerais e ao futebol em específico, nenhuma outra modalidade é citada. Embora seja possível estabelecer relações com outras modalidades, não é essa a intenção do artigo, nem a expertise maior dos autores.

O processo de formação de treinadores e jogadores esteve, por muito tempo, concebido a partir de uma perspectiva positivista, sendo que, ainda hoje, esse panorama persiste em muitas esferas desse contexto. Em contraste com as abordagens de cunho positivista, as abordagens interacionistas não progridem de forma linear, com respostas determinadas, mas procurando dar sentidos aos fenômenos sociais a partir da interação de seus elementos (WENGER, 2013). Assim, para pensar a formação de treinadores e jogadores de futebol, é relevante considerar a interação entre os personagens do ambiente (CHOW, 2013), as disposições do contexto e 0 direcionamento da formação (NELSON; CUSHION; POTRAC, 2006), bem como as situações de aprendizagem (TRUDEL; CULVER; WERTHNER, 2013). Há de se considerar, também, que estão em momentos diferentes de sua biografia e trajetória: treinadores tendem a ter mais experiências e oportunidades de aprendizagem, enquanto jogadores muitas vezes estão em momentos anteriores de seu processo de formação. Logo, um aprende na interação com o outro, mas cada um tem necessidades específicas de seu momento, trajetória e papel no processo: treinar e jogar, respectivamente.

Para a formação de treinadores, os gestores de clubes de futebol podem compreender, a partir da Aprendizagem ao Longo da Vida (JARVIS, 2006), que a essência é moldada pela interação com o mundo. O estímulo para a aprendizagem vem da nossa experiência, o ponto que fazemos intersecção com o mundo, tanto físico quanto social, e vamos incorporando as aprendizagens de tais experiências em nossa biografia individual (JARVIS, 2013). Nessa 
perspectiva, é importante que os clubes organizem situações de aprendizagem significativas para os treinadores, para que operacionalizem suas experiências práticas e também aprendam com elas (TOZETTO; GALATTI; MILISTETD, 2018).

Se o tema da formação de treinadores no clube, de maneira mais sistemática e intencional, é uma discussão mais nova, as propostas para a formação de jogadores são mais recorrentes e diversas na literatura a partir de teorias inatistas, empiristas ou interacionistas (GALATTI et al., 2014; SCAGLIA et al., 2013); na própria especificidade do futebol são diversas as propostas contemporâneas (BETTEGA et al., 2015). Na formação dos jogadores, uma sugestão de sustentação do processo é apresentada pela Pedagogia Não Linear (PNL) (CHOW et al., 2015; MACHADO et al., 2019), que busca, através da manipulação dos constrangimentos da tarefa ${ }^{1}$, estimular a exploração das informações do contexto de jogo. A PNL é indicada neste texto por compreender o treinador como um agente em formação que visa estimular o desenvolvimento de jogadores buscando atender o cenário complexo e não linear do jogo, sendo papel do treinador a criação de oportunidades de interação do jogador com o meio, facilitando, assim, o desenvolvimento da tomada de decisão e a conscientização das diferentes ações realizadas no jogo (CHOW et al., 2013).

O processo necessita ser contextualizado, havendo a mudança de objetos para relações, ou seja, o treinador e o jogador não podem ser compreendidos como objetos que recebem e acumulam conhecimento, mas como sujeitos ativos que interagem, criando relações e aprendendo principalmente em seus contextos de prática (JONES, MORGAN; HARRIS, 2012). Os treinadores, em um processo de sempre aprender, tendem a melhor organizar 0 ambiente com tarefas representativas, estimulando os jogadores ao aprendizado constante e otimizando suas interações com o futebol e sua natureza complexa. Assim, propiciar situações de aprendizagem aos treinadores em meio às suas intervenções práticas e, circunstancialmente, aos jogadores a partir das interações na resolução das tarefas tende a facilitar a compreensão das ações para ambos.

Portanto, pensando a formação de treinadores e jogadores de forma interligada em meio ao ambiente do clube de futebol e considerando as peculiaridades de cada função, este ensaio teórico de cunho descritivo-reflexivo tem como objetivo apresentar possibilidades para formação de treinadores e jogadores de futebol, considerando as particularidades dos processos de aprendizagem e momento de vida/biografia de cada um desses personagens, mas também a interação entre o treinador e o jogador no cenário do clube e especificamente no treino.

\section{PROCESSO DE FORMAÇÃO DOS TREINADORES NO FUTEBOL}

A formação de pessoas na sociedade contemporânea precisa acompanhar as novas possibilidades de interação, reconhecendo as particularidades do cenário atual. $O$ pensamento social no fim do século XIX e início do século XX foi muito influenciado pelo positivismo, doutrina formulada pelo filósofo social Auguste Comte e claramente padronizada de acordo com a física newtoniana. Tal doutrina enfatiza a quantificação e rejeita todas as explicações que recorrem a fenômenos subjetivos, sustentando as diretrizes de muitas instituições de ensino até os dias atuais. Entretanto, ao formar pessoas, e nesse caso treinadores de futebol

\footnotetext{
1 Segundo Newell (1986), constrangimentos podem ser compreendidos como limitações que moldam o comportamento dos sistemas de movimento (ex.: jogadores). Já constrangimentos da tarefa são caracterizados pelo objetivo e regras que definem a dinâmica contextual de um jogo (ou mesmo exercício utilizado durante as sessões de treino) (ARAÚJO; PASSOS; ESTEVES, 2011).
} 
no contexto contemporâneo, é necessário pensar de forma sistêmica, atribuindo importância à conectividade, às relações, aos padrões e ao contexto (CAPRA; LUISI, 2014).

Senge (2011) ressalta que, a partir do final do século XX, a humanidade conseguiu criar muito mais informações do que o homem pode aprender, logo, não basta haver uma única pessoa aprendendo, seguindo ordens e reproduzindo soluções prontas, é necessário possibilitar que a organização e as pessoas cultivem o comprometimento e a capacidade de aprender em todos os níveis da organização. No caso da formação de treinadores, a aprendizagem deve ser centrada no indivíduo, reconhecendo suas necessidades e potencialidades, bem como auxiliando o desenvolvimento de competências ao longo da vida, sendo essas relacionadas com seus contextos de inserção (RODRIGUE; HE; TRUDEL, 2016; TOZETTO; GALATTI; MILISTETD, 2018).

Jarvis (2013) destaca que a aprendizagem humana acontece por meio de processos ao longo da vida, cujo conteúdo é percebido, transformado e integrado à biografia individual da pessoa. A compreensão da realidade social direciona a aprendizagem e aproxima o indivíduo dos fenômenos e deve ser reconhecida a partir da cultura que é criada e sustentada por uma rede (forma) de comunicações (processo) que gera o significado, passado através das incorporações materiais (matéria) da cultura ao longo das gerações (CAPRA, 2002). Ou seja, o desenvolvimento do aprendizado do treinador de futebol ocorre com base na forma como os ambientes são estruturados, as relações são estabelecidas e os significados são incorporados e materializados ao longo do tempo.

A concepção da Aprendizagem ao Longo da Vida nos permite ampliar quais são as experiências significativas para potencializar o desenvolvimento dos treinadores (TOZETTO et al., 2017). A formação centrada no treinador não coloca no centro da aprendizagem 0 que é meramente aprendido, mas no que o sujeito está se tornando a partir da sua forma de fazer, pensar e sentir (JARVIS, 2006). Nessa perspectiva, a aprendizagem é concebida como uma rede em que 0 treinador interage com as oportunidades de aprendizagem a partir das suas disposições, buscando a compreensão e não a memorização, tornando o aprendizado significativo (TRUDEL; CULVER; WERTHNER, 2013).

A própria prática do treinador é fonte de aprendizagem e o local de atuação é contexto fundamental para pensar o seu desenvolvimento. A intervenção do treinador em meio ao clube sofre constantes interferências internas e externas, isto é, na relação com jogadores, membros da comissão técnica e dirigentes, bem como no âmbito externo com a torcida, empresários, mídia e demais agentes do contexto. Logo, é possível ressaltar a necessidade de o aprendizado ser contextualizado com o cotidiano do treinador, sistematizado e estimulado a partir de situações de aprendizagem mediadas, não mediadas e internas (TRUDEL; CULVER; WERTHNER, 2013).

As situações de aprendizagem mediadas não são definidas pelo indivíduo, mas por instrutores que direcionam o conteúdo e a forma de desenvolvimento. Nas situações de aprendizagem não mediadas a escolha das oportunidades é determinada pelos treinadores, ocorrendo nas interações estabelecidas com outros personagens do contexto. As situações de aprendizagem internas contemplam a reflexão e reorganização do conhecimento estabelecidos nas situações vivenciadas (TRUDEL; CULVER; WERTHNER, 2013). Tais situações devem fazer sentido para os treinadores, para assim otimizar suas competências profissionais, interpessoais e intrapessoais (GILBERT; CÔTÉ, 2013). 
No âmbito profissional, principal foco dos contextos formais e não formais de formação, o treinador precisa obter conhecimento sobre a funcionalidade do jogo, suas regras e estrutura, bem como sobre as disposições do esporte, as características dos jogadores e o processo de ensino-treino. Nas questões interpessoais, é importante conhecer o contexto social de inserção, realizar uma boa gestão dos relacionamentos e saber se expressar e intervir nas diferentes situações apresentadas. No tocante à comunicação intrapessoal, a compreensão e a constante autorreflexão sobre as suas dificuldades, qualidades e possibilidades tendem a facilitar a construção da filosofia de trabalho e os processos de aprendizagem do treinador (BETTEGA et al., 2017).

As oportunidades de aprendizagem e transformação do comportamento e pensamento do treinador de futebol passam pela sua motivação e interesse, bem como pelas possibilidades estabelecidas no contexto de inserção, nesse caso, o clube de futebol. Nesse sentido, o clube precisa proporcionar situações para que os treinadores aprendam na sua intervenção, ou seja, na relação com os jogadores, membros da comissão técnica, na troca com os pares, na participação de reuniões, seminários e cursos e na reflexão e reorganização de suas ações diárias. Assim, tais situações de ocorrência cotidiana na vida do treinador precisam trazer significado, alternando sua forma de pensar e agir e transformando constantemente suas práticas.

\section{O PROCESSO DE FORMAÇÃO DE JOGADORES DE FUTEBOL}

No clube de futebol o processo de desenvolvimento de jogadores tem grande destaque, uma vez que a formação de atletas de excelência poderá promover inúmeros benefícios ao clube, tanto no âmbito financeiro como no competitivo (SORIANO, 2010). Nesse âmbito, o processo de ensino-treino no futebol se consolidou no século XX por pressupostos de uma Ciência Tradicional, entendendo a aprendizagem como um processo linear (CHOW et al., 2015). Pautado numa visão cartesiana, o treino passou a ser altamente individualizado, sustentando que uma boa atuação coletiva no jogo se dá por meio da soma do desempenho individual de cada jogador, tendo em conta suas principais características, a simplicidade (o mundo e os objetos podem ser divididos em partes), a estabilidade (previsibilidade dos fenômenos) e a objetividade (versão única do conhecimento) (GALATTI et al., 2014). Esse processo acabou tendo implicações importantes e, muitas vezes, negativas, para a aprendizagem, como, por exemplo: a) organização do processo por níveis (do mais simples para o mais complexo); b) o foco na relação entre o jogador e a bola (componente técnica); c) a existência de modelos predeterminados (o jogador de elite), dentro do qual o indivíduo necessita se enquadrar; e d) é necessário repetir para automatizar (GALATTI et al., 2014).

Em estudo realizado por Ford, Yates e Williams (2010), é possível constatarmos um processo de ensino-treino que tem as características supramencionadas, em que os treinadores optam pela utilização de uma quantidade maior de atividades descontextualizadas. Além disso, observaram que os treinadores costumam fornecer altos níveis de instrução e feedback, logo, cerceando as possibilidades de tomada de decisão dos jogadores e dificultando a compreensão da lógica interna do jogo, bem como tornando-os altamente dependentes do treinador para agir (GALATTI et al., 2014)

Contrapondo essa perspectiva positivista, Chow e colaboradores (2015) defendem a necessidade de compreensão da aprendizagem como um processo não linear, dinâmico e complexo, tendo em conta a relação estabelecida entre o jogador, ambiente e a tarefa (CHOW; 
ATENCIO, 2014). Para os autores, a aprendizagem não ocorre através de uma transmissão direta e linear de um conhecimento específico do treinador para o jogador, mas emerge a partir da interação entre 0 indivíduo e 0 ambiente, contexto este em que 0 treinador também está inserido, tendo um papel crucial para a eficácia do processo. Portanto, o jogador, o treinador e o ambiente podem ser compreendidos como um sistema dinâmico e complexo em que, através de suas interações, a aprendizagem poderá ser potencializada, tanto do treinador quanto do jogador (CHOW et al., 2013).

Logo, partindo desse pressuposto, é importante referir que a aprendizagem precisa ser contextualizada, pois é nela que o jogador desenvolve e aprimora suas habilidades e competências por meio do jogo. A PNL pode ser compreendida como uma abordagem teórica que norteia a elaboração de um processo de ensino centrado no indivíduo e pautado no jogo, compreendendo que a aprendizagem emerge da interação desse indivíduo com o ambiente (CHOW et al., 2015; SERRA-OLIVARES et al., 2015). A PNL, por meio da criação de um ambiente de aprendizagem significativo, procura estimular uma participação ativa do jogador no próprio processo de aprendizagem. Desse modo, a partir da utilização de princípios pedagógicos-chave, o treinador poderá manipular cuidadosamente os constrangimentos da tarefa para estimular que os jogadores explorem o contexto e enriqueçam o seu acervo de soluções para os problemas impostos pelo jogo (REVERDITO; SCAGLIA, 2007; CHOW et al., 2015).

Machado e colaboradores (2019) apresentam a PNL como uma abordagem adequada para sustentar metodologicamente o ensino-treino sistematizado do futebol, uma vez que os princípios ali propostos permitem que treinadores sejam facilitadores do processo de aprendizagem de quem joga, tendo por premissa o jogo. São eles: representatividade das tarefas; acoplamento funcional informação-ação; manipulação de constrangimentos; aprendizagem exploratória e atenção focada. Logo, o treinador buscará equilibrar os constrangimentos da tarefa para criar exercícios que estimulem um acoplamento funcional entre informação e ação (CHOW, 2013). Além disso, o treinador necessita refletir acerca do modo de intervenção durante o processo, passando a ser um agente facilitador desse processo através da criação de ambientes que estimulem os jogadores a explorarem uma variedade de padrões de movimento funcionais e que desenvolvam o prazer e a paixão pelo jogo (RENSHAW et al., 2009; RENSHAW; OLDHAM; BAWDEN, 2012). Sustentados por pressupostos de uma abordagem pedagógica de cunho interacionista, não linear, dinâmica e complexa, diversos autores procuram apoiar a elaboração de propostas de ensino pautadas no jogo (SCAGLIA, 2003; REVERDITO; SCAGLIA, 2007; REVERDITO; SCAGLIA; PAES, 2009; SCAGLIA; REVERDITO; GALATTI, 2013).

Assim, o ambiente de jogo pode ser considerado um importante ambiente de aprendizagem, no qual a compreensão acerca do processo organizacional sistêmico ganha um importante destaque (REVERDITO; SCAGLIA, 2007; SCAGLIA; REVERDITO; GALATTI, 2013; SCAGLIA et al., 2013). Ou seja, é necessário entender como o jogo se organiza para propor um processo de ensino que seja pautado nele e que estimule o desenvolvimento concomitante das componentes físicas, técnicas e táticas. Assim, o treinador poderá gerir melhor os constrangimentos-chave do jogo (tarefa), procurando adaptá-lo aos níveis de desempenho e aos estágios de aprendizagem dos seus jogadores, bem como aos objetivos pedagógicos (ATENCIO et al., 2014; BETTEGA et al., 20152; CHOW et al., 2015).

20 artigo de Bettega e colaboradores (2015) apresenta uma proposta pedagógica para o processo de ensino-treino no futebol, elencando princípios para serem desenvolvidos em diferentes etapas da formação. 


\section{A FORMAÇÃO DE TREINADORES E JOGADORES E AS FUNDAMENTAIS RELAÇÕES NO PROCESSO}

Com base nas discussões acerca do processo de formação do treinador e do jogador, fica clara a necessidade de se romper o paradigma positivista, uma vez que, a partir de nosso referencial, esse processo precisa ser visualizado dentro do arcabouço interacionista. Ou seja, o texto alicerçado no bojo interacionista pauta-se na perspectiva sistêmica e complexa (CAPRA; LUISI, 2014), compreendendo que a aprendizagem emerge da interação interna do indivíduo e com 0 ambiente. $O$ olhar sobre 0 texto transita entre 0 indivíduo e 0 ambiente, mas repousa e busca fortalecer a interação entre ambos. Destacamos que a proposta não se apresenta como melhor ou pior que outras, mas se estabelece como um caminho interessante para essa mudança de perspectiva paradigmática.

O processo de formação do treinador foi pautado em âmbito geral na Aprendizagem ao Longo da Vida (JARVIS, 2006), que compreende a aprendizagem como a combinação de processos ao longo da vida, a partir das situações de experiência social cujo conteúdo percebido é transformado através da cognição, emoção ou prática. Na formação do jogador, foi abordada a PNL (CHOW; ATENCIO, 2014), que se sustenta na psicologia ecológica e na teoria dos sistemas dinâmicos, evidenciando a interação do indivíduo com o ambiente. Também buscamos apresentar as situações de aprendizagem como mediadas, não mediadas e internas (TRUDEL; CULVER; WERHNER, 2013). Por diferentes bases teóricas, ressaltamos a necessidade de o clube (a partir de seus gestores), como principal contexto de formação para treinadores e jogadores, compreender que ambos os processos de formação (jogador e treinador) estão diretamente interligados e passam por questões de âmbito profissional, social e pessoal.

O contexto de treino, principal ponto de intersecção entre treinadores e jogadores, é fonte de aprendizagem e caminho mais assertivo e intencional para otimização do desempenho de treinadores e jogadores se organizado, sistematizado, aplicado e avaliado de forma coerente e especialmente se sustentado no conhecimento científico adequado, que não se limite a uma concepção positivista (GALATTI et al., 2014). Um dos principais cenários de aprendizagem do treinador é o mesmo que o do jogador: o treino. Assim, necessita planejar conteúdos condizentes com a etapa de desenvolvimento dos jogadores, adaptando suas ações a partir dos acontecimentos das relações estabelecidas em treino e jogo. $O$ treinador deve criar atividades de treino que estimulem a resolução de problemas, desafiando os jogadores a buscarem soluções, explorando a sua autonomia e criatividade (BETTEGA et al., 2015; GALATTI et al., 2015). A constante construção e reconstrução do cenário de treino a partir da criação de situações-problema tende a estimular a interação com os jogadores, causando transformações e facilitando o processo de aprendizagem.

A interação entre treinador e jogador passa pela forma como o ambiente é arquitetado, através de jogos que busquem manipular os elementos estruturais para os jogadores explorarem as informações no jogo e também por jogos que visam à manipulação das regras para induzir o comportamento dos jogadores, desenvolvendo competências profissionais, sociais e pessoais (GALATTI et al., 2016). Com base na forma de comunicação, realizada por meio de instrução, questionamento, feedback e modelagem (VICKERS, 2003), a abordagem do conteúdo pode ser implícita (sem exposição dos objetivos, somente das regras dos jogos) e explícita (expondo os objetivos e estimulando a sua busca). Isso posto, evidenciamos a necessidade de o treinador 
apresentar processos de sistematização de tais situações, proporcionando ações de ensino intencionais e estabelecendo processos de aprendizagem a partir da interação significativa entre treinador e jogador. Da mesma forma, é na aplicação das atividades e avaliação das respostas de jogadores e autoavaliação de sua intervenção junto a eles que treinadores vão aprendendo constantemente a propor tarefas e melhor organizar o ambiente de aprendizagem de atletas.

Os processos de formação em longo prazo, do treinador e do jogador, configuram-se altamente complexos e influenciados por inúmeros fatores. Logo, temos que: (1) treinador e jogador aprendem ao longo da vida; (2) a aprendizagem é não linear; (3) treinador aprende para melhor estimular o jogador; (4) jogador é fonte de aprendizagem do treinador e treinador é fonte de aprendizagem ao jogador: a interação é fundamental para o desenvolvimento de pessoas no futebol e também em outras manifestações esportivas. Tendo em conta essa complexidade, Côté e colaboradores (2017), ao proporem o Quadro Teórico de Valores Pessoais no Esporte, procuram destacar a importância da interação de três elementos dinâmicos que acabam contribuindo para o desenvolvimento de valores pessoais dos participantes do contexto esportivo. Para os autores, o cenário apropriado (cenários que cercam o contexto de convivência do treinador e do jogador), o engajamento pessoal (atividades específicas que contribuem diferentemente para a qualidade de suas experiências esportivas) e a qualidade dos relacionamentos (relações interpessoais estabelecidas no esporte) que são estabelecidos entre o indivíduo e outros agentes envolvidos no processo (pais, dirigentes, pares, etc.) contribuem diretamente para o desenvolvimento da competência, confiança, conexão e caráter do sujeito.

Em longo prazo, uma harmônica disposição entre os elementos dinâmicos e os valores pessoais poderá contribuir para uma maior participação, desempenho e desenvolvimento pessoal através da prática esportiva (CÔTÉ; ABERNETHY, 2012). A Figura 2 apresenta a interação entre treinador e jogador em meio ao clube, sustentados pelos elementos dinâmicos e direcionados pelas situações de aprendizagem mediadas, não mediadas e internas e que convergem para o desenvolvimento de competências profissionais, pessoais e sociais.

Figura 1 - Representação da interação e disposição dos elementos na formação do treinador e jogador de futebol.

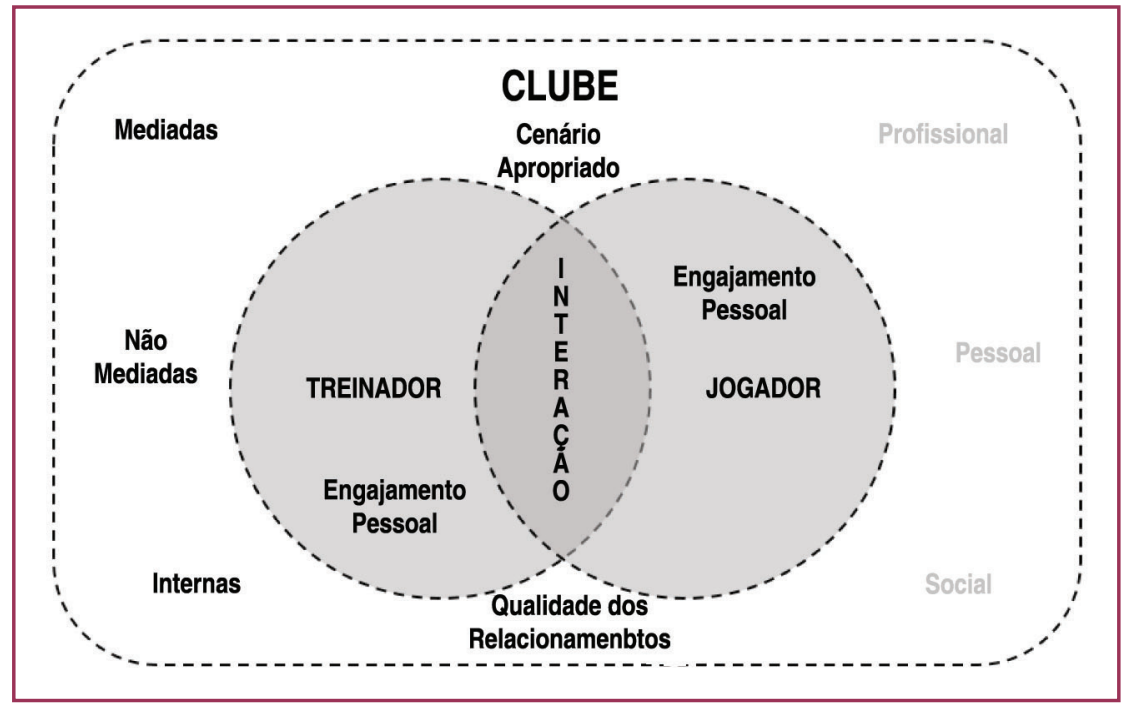

Fonte: Elaborado pelos autores. 
Compreendendo a importância da formação do treinador e do jogador de futebol, tornase relevante a criação de oportunidades de vivenciar diferentes situações de aprendizagem para o desenvolvimento do jogador e do treinador. Nesse sentido, o Quadro 1 procura destacar de que forma o clube, a partir de seus gestores, poderá proporcionar diferentes situações de aprendizagem para ambos. Aqui, o clube será reconhecido enquanto uma organização de aprendizagem (MILISTETD et al., 2017), tendo o papel de agente facilitador, procurando criar contextos que facilitem o desenvolvimento do treinador e do jogador e promovendo uma aprendizagem significativa.

Quadro 1 - 0 papel do clube enquanto organização de aprendizagem.

\begin{tabular}{|c|c|c|}
\hline $\begin{array}{c}\text { Papel do clube } \\
\text { enquanto organização } \\
\text { de aprendizagem em } \\
\text { proporcionar: }\end{array}$ & Na formação do jogador & Na formação do treinador \\
\hline $\begin{array}{c}\text { Situações de } \\
\text { aprendizagem } \\
\text { mediadas }\end{array}$ & $\begin{array}{c}\text { Proporcionar um processo de ensino- } \\
\text { treino organizado, estruturado, que } \\
\text { procure estimular o desenvolvimento do } \\
\text { jogador através de uma proposta pautada } \\
\text { no jogo. }\end{array}$ & $\begin{array}{c}\text { Proporcionar ao treinador a } \\
\text { participação em cursos, workshops, } \\
\text { palestras. }\end{array}$ \\
$\begin{array}{c}\text { Situações de } \\
\text { aprendizagem não } \\
\text { mediadas }\end{array}$ & $\begin{array}{c}\text { Ao possibilitar o acesso a um treino } \\
\text { pautado no jogo e proporcionar ao } \\
\text { jogador o desenvolvimento da motivação } \\
\text { intrínseca, ele será estimulado a continuar } \\
\text { criando situações de aprendizagem em } \\
\text { contextos informais, como através do jogo } \\
\text { deliberado ou da prática espontânea4 }\end{array}$ & $\begin{array}{c}\text { Proporcionar ao treinador encontros e } \\
\text { discussões com outros treinadores e/ } \\
\text { ou membros das diferentes comissões } \\
\text { técnicas. }\end{array}$ \\
\hline $\begin{array}{c}\text { Situações de } \\
\text { aprendizagem } \\
\text { internas }\end{array}$ & $\begin{array}{c}\text { Passar tarefas para os jogadores } \\
\text { realizarem entre as sessões de treino, } \\
\text { como, por exemplo, assistir jogos } \\
\text { na televisão, poderá estimular uma } \\
\text { reflexão sobre determinados conteúdos } \\
\text { trabalhados nas sessões de treino. }\end{array}$ & $\begin{array}{c}\text { Estabelecer a construção de } \\
\text { e jogos, sendo que esses poderão } \\
\text { treinador sobre sua prática, tornando-o } \\
\text { um agente ativo na produção da } \\
\text { própria aprendizagem. }\end{array}$ \\
\hline
\end{tabular}

Fonte: Elaborado pelos autores.

O clube que promove o futebol profissional, que tem transitado na atualidade do âmbito associativo para o empresarial (GALATTI, 2010), independentemente de seus objetivos particulares enquanto características, se configura como ambiente formativo e deve estabelecer estratégias para direcionar a formação. Milistetd e colaboradores (2017) destacam aspectos referentes à reorganização do processo de formação de treinadores de elite, sendo possível compreender a importância do próprio ambiente de trabalho enquanto estrutura que possibilita 0 desenvolvimento profissional, reconhecendo que o clube tem um grande potencial para promover situações de aprendizagem. Apesar dos autores focarem no processo de formação de treinadores de elite, o clube também se mostra como contexto de aprendizagem que, se corretamente organizado e estruturado, poderá potencializar o desenvolvimento de jogadores e treinadores em longo prazo.

\footnotetext{
3 Jogo deliberado: prática organizada pelo próprio indivíduo com o objetivo de saciar o seu desejo e vontade em jogar futebol (Côté; Erickson; Abernethy, 2013). Ex.: futebol de rua.

4 Prática espontânea: prática organizada pelo próprio indivíduo com o objetivo de melhor seu desempenho em algum domínio (técnico, tático, físico ou fisiológico) (Côté; Erickson; Abernethy, 2013).
} 
No clube, especificamente o cenário de treino configura um ponto de intersecção relevante para formação do treinador e do jogador de futebol, logo, precisa ser explorado e organizado para facilitar a aprendizagem de ambos. Nessa perspectiva, pensar a formação do treinador e do jogador a partir da interação em situações reais e com possibilidades funcionais explícitas poderá facilitar a aprendizagem, bem como torná-la mais significativa. Desse modo, o que nos interessa no fenômeno de investigação não são os conhecimentos adquiridos, mas os princípios organizadores que podem nos trazer, não a certeza, mas a diversidade e a multiplicidade de conhecimentos (PENA-VEJA, 2003).

Assim, criar um ambiente eficaz para o desenvolvimento do treinador em meio ao clube não facilita apenas os seus processos de aprendizagem, mas também as suas possibilidades de intervenção. Logo, contribui nas interações com os jogadores e tende a viabilizar e auxiliar também o processo de formação desses. Ou seja, precisamos estar mais conscientes da necessidade de ser menos prescritivos em nossas instruções e aceitar que devemos desempenhar um papel facilitador no processo de formação de pessoas no ambiente esportivo (CHOW et al., 2013).

\section{CONSIDERAÇÕES FINAIS}

Criar ambientes para formação de pessoas, na perspectiva da interação, contempla uma tarefa um tanto quanto complexa. No caso do futebol, a formação de treinadores e jogadores ainda é em muitas situações conduzida pelo empirismo, sem uma devida sistematização. Assim, procuramos no decorrer do texto apresentar possibilidades para a formação do treinador e do jogador de futebol indicando algumas particularidades, mas buscando aproximar o processo formativo no clube de futebol e especificamente no contexto de treino.

Na formação do treinador, sustentamos nossas reflexões e inferências na aprendizagem ao longo da vida, que enfatiza 0 aprendizado a partir dos episódios da vida, em que 0 indivíduo interage com o mundo e vive em constante transformação. Para o estímulo da formação do jogador, enfatizamos como expressivo o embasamento do processo por meio de uma Pedagogia Não Linear, que busca apresentar tarefas representativas, estimulando um acoplamento funcional entre informação e ação, bem como a exploração de uma variedade de padrões de movimentos funcionais. Na aproximação da formação do jogador e treinador de futebol, é interessante a projeção de situações de aprendizagem mediadas, não mediadas e internas, podendo o cenário de treino ser um relevante contexto para a ocorrência e estímulo de tais situações.

Portanto, a formação de treinadores e jogadores de futebol emerge das suas rotinas particulares, crenças e da interação com diversos agentes de diferentes contextos. Entretanto, destacamos que a organização, sistematização, aplicação e avaliação consistente do treino facilitará a interação entre treinador e jogador e, assim, estabelecer possibilidades intensas, conscientes e significativas de aprendizado para ambos, ao longo da vida. 


\section{REFERÊNCIAS}

ARAÚJO, Duarte; PASSOS, Pedro; ESTEVES, Pedro. Teoria do treino da Tomada de Decisão no Desporto. In: ALVES, José; Brito, António Paula (eds.). Manual de Psicologia do Desporto para Treinadores. Lisboa: Visão e Contextos, 2011. p. 265-294.

ATENCIO, Matthew et al. Using a complex and nonlinear pedagogical approach to design practical primary physical education lessons. European Physical Education Review, v. 20, n. 2, p. 244-263, 2014.

BETTEGA, Otávio Baggiotto et al. Formação de jogadores de futebol: princípios e pressupostos para composição de uma proposta pedagógica. Movimento, v. 21, n. 3, p.791-801, 2015.

BETTEGA, Otávio Baggiotto et al. Papéis do treinador esportivo de categorias de base nos jogos esportivos coletivos. In: GALATTI, Larissa Rafaela et al. (orgs.). Desenvolvimento de treinadores e atletas: pedagogia do esporte. Campinas: Editora da Unicamp, 2017. p. 45-57.

CAPRA, Fritjof. As conexões ocultas: ciência para uma vida sustentável. São Paulo: Cultrix, 2002.

CAPRA, Fritjof; LUISI, Pier. A visão sistêmica da vida: uma concepção unificada e suas implicações filosóficas, políticas, sociais e econômicas. São Paulo: Cultrix, 2014.

$\mathrm{CHOW}$, Jia Yi et al. The acquisition of movement skill in children through nonlinear pedagogy. In: CÔTÉ, Jean; LIDOR, Ronnie (eds.). Conditions of children's talent development in sport. Morgantown: FIT, 2013. p. 41-59.

CHOW, Jia Yi. Nonlinear learning underpinning pedagogy: evidence, challenges and implications. Quest, v. 65, n. 4, p. 469-484, 2013.

CHOW, Jia Yi; ATENCIO, Matthew. Complex and nonlinear pedagogy and the implications for physical education. Sport, Edcation and Society, v. 19, n. 8, p. 1034-1054, 2014.

CHOW, Jia Yi et al. Nonlinear Pedagogy in Skill Acquisition: an introduction. London: Routledge, 2015.

CÔTÉ, Jean; ABERNETHY, Bruce. A developmental approach to sport expertise. In: MURPHY, Shane (ed.). Oxford Handbook of Sport and Performance Psychology. New York: Oxford University, 2012. p. 435-447.

CÔTÉ, Jean; ERICKSON, Karl; ABERNETHY, Bruce. Play and practice during childhood. In: CÔTÉ, Jean; LIDOR, Ronnie. (eds.). Conditions of children's talent development in sport. FIT, 2013. p. 09-20.

CÔTÉ, Jean et al. Quadro teórico para o desenvolvimento de valores pessoais no processo dinâmico de desenvolvimento pelo esporte. In: GALATTI, Larissa Rafaela et al. (orgs.). Múltiplos cenários da prática esportiva: pedagogia do esporte. v. 2. Campinas: Editora da Unicamp, 2017. p. 15-40.

FORD, Paul; YATES, lan; WILLIAMS, Mark. An analysis of practice activities and instructional behaviours used by youth soccer coaches during practice: exploring the link between science and application. Journal of Sports Sciences, v. 28, n. 5, p. 483-495, 2010. 
GALATTI, Larissa Rafaela. Esporte e Clube Sócio-esportivo: percurso, contextos e perspectivas a partir de estudo de caso em clube esportivo espanhol. 2010. 305f. (Tese de Doutorado em Educação Física). Faculdade de Educação Física, Universidade Estadual de Campinas, Campinas, 2010.

GALATTI, Larissa Rafaela et al. Pedagogia do esporte: tensão na ciência e o ensino dos jogos esportivos coletivos. Revista da Educação Física/UEM, v. 25, n. 1, p. 153-162, 2014.

GALATTI, Larissa Rafaela et al. Atribuições do professor e treinador de esporte: ensino do futebol em idade escolar. In: FEU, Sebastián; CAÑADAS, Maria (eds.). Innovaciones y aportaciones a la formación de entrenadores para el deporte en la edad escolar. [Cáceres Campinas]: Universidad de Extremadura e Unicamp, 2015.p. 239-251.

GALATTI, Larissa Rafaela et al. Coaches perceptions of youth players development in a professional soccer club in Brazil: paradoxes between the game and those who play. Sports Coaching Review, v. 5, n. 2, p. 174-185, 2016.

GILBERT, Wade; CÔTÉ, Jean. Defining coaching effectiveness: a focus on coaches' knowledge. In: GILBERT, Wade; DENISON, Jim (eds.). Routledge Handbook of Sports Coaching. London: Routledge, 2013.p. 147-159.

JARVIS, Peter. Towards a comprehensive theory of learning. London: Routledge, 2006.

JARVIS, Peter. Aprendendo a ser uma pessoa na sociedade: aprendendo a ser eu. In: ILLERIS, Knud (org.). Teorias contemporâneas da aprendizagem. Porto Alegre: Editora Penso, 2013. p. 31-45.

JONES, Robyn; MORGAN, Kevin; HARRIS, Kerry. Developing coaching pedagogy: seeking a better integration of theory and practice. Sport, Education and Society, v. 15, n. 2, p. 1-17, 2012.

MACHADO, João Claúdio et al. Enhancing learning in the context of street football: a case for nonlinear pedagogy. Physical Education and Sport Pedagogy, v. 24, n. 2, p. 176-189, 2019.

MILISTETD, Michel et al. Formação do treinador para o esporte de elite. In: GALATTI, Larissa Rafaela et al. (orgs.). Desenvolvimento de treinadores e atletas: pedagogia do esporte. Campinas: Editora da Unicamp, 2017. p. 39-61.

NELSON, Lee; CUSHION, Christopher; POTRAC, Paul. Formal, nonformal and informal coach learning: a holistic conceptualization. International Journal of Sports Science \& Coaching, v. 1, n. 3, p. 247-259, 2006.

NEWELL, Karl. Constraints on the development of coordination. In: WADE, Michael; WHIRING, Harry (eds.). Motor Skill Acquisition in Children: aspects of coordination and control. Boston, MA: Nihjoff, 1986. p. 341-360.

PENA-VEJA, Alfredo. 0 despertar ecológico: Edgar Morin e a ecologia complexa. Rio de Janeiro: Garamond, 2003.

RENSHAW, lan et al. Insights from ecological psychology and dynamical systems theory can underpin a philosophy of coaching. International Journal of Sport Psychology, v. 40, n. 4, p. 540-602, 2009.

RENSHAW, Ian; OLDHAM, Anthony; BAWDEN, Mark. Nonlinear pedagogy underpins intrinsic motivation in sports coaching. The Open Sports Sciences Journal, v. 5, p. 88-99, 2012.

REVERDITO, Riller; SCAGLIA, Alcides José. A gestão do processo organizacional do jogo: uma proposta metodológica para o ensino dos jogos coletivos. Motriz, v. 13, n. 1, p. 51-63, 2007. 
REVERDITO, Riller; SCAGLIA, Alcides José; PAES, Roberto. Pedagogia do esporte: panorama e análise conceitual das principais abordagens. Motriz, v. 15, n. 3, p. 600-610, 2009.

RODRIGUE, François; HE, Chao; TRUDEL, Pierre. Concept Mapping: Its use for high performance sport coach development. In: DAVIS, Paul (ed.). The Psychology of Effective Coaching and Management. Hauppauge: Nova Science, 2016. p. 71-90.

SCAGLIA, Alcides José. 0 futebol e os jogos/brincadeiras de bola com os pés: todos semelhantes, todos diferentes. 2003. $178 f$ (Tese de Doutorado) - Faculdade de Educação Física, Universidade Estadual de Campinas, Campinas, 2003.

SCAGLIA, Alcides; REVERDITO, Riller; GALATTI, Larissa. Ambiente de jogo e ambiente de aprendizagem no processo de ensino dos jogos esportivos coletivos: desafios no ensino e na aprendizagem dos jogos esportivos coletivos. In: NASCIMENTO, Juares; RAMOS, Valmor; TAVARES, Fernando. (orgs.). Jogos Desportivos: formação e investigação. Florianópolis: Tribo da llha, 2013. p. 133-170.

SCAGLIA, Alcides José et al. O ensino dos jogos esportivos coletivos: as competências essenciais e a lógica do jogo em meio ao processo organizacional sistêmico. Movimento, v. 19, n. 4, p. 227-249, 2013.

SENGE, Peter. A quinta disciplina: arte e prática da organização que aprende. Rio de Janeiro: Bestseller, 2011.

SERRA-OLIVARES, Jaime et al. Game-based approaches pedagogical principles: exploring task constraints in youth soccer. Journal of Human Kinetics, v. 46, n. 1, p. 251-261, 2015.

SORIANO, Ferran. A bola não entra por acaso. São Paulo: Larousse Brasil, 2010.

TOZETTO, Alexandre et al. Football coaches' development in Brazil: a focus on the content of learning. Motriz, v. 23, n. 3, e101712, 2017.

TOZETTO, Alexandre; GALATTI, Larissa Rafaela; MILISTETD, Michel. Desenvolvimento professional de treinadores esportivos no Brasil: perspectiva de aprendizagem ao lono da vida. Pensar a Prática, v. 21, n. 1, p. 207-217, 2018.

TRUDEL, Pierre; CULVER, Diane; WERTHNER, Penny. Looking at coach development from the coach-learner's perspective: considerations for coach development administrator. In: POTRAC, Paul; GILBERT, Wade; DENISON, Jim (eds.). Routledge Handbook of Sports Coaching. London: Routledge, 2013. p. 375-387.

VICKERS, Joan. Decision training: An innovative approach to coaching? Canadian Journal for Women Coaches Online, v. 3, n. 3, p. 3-9, 2003.

WENGER, Etienne. The practice of theory: confessions of a social learning theorist. . In: FARNSWORTH, Valerie; SOLOMON, Yvette. (eds.), Reframing Educational Research: Resisting the 'what works' agenda. London: Routledge, 2013. p. 105-118.

\section{Apoio:}

Fundação de Amparo à Pesquisa do Estado de São Paulo (FAPESP), projeto número 2017/12142-5. 